\title{
PENGARUH SENAM POCO-POCO TERHADAP KADAR KOLESTEROL LOW DENSITY LIPOPROTEIN DARAH
}

\author{
${ }^{1}$ Asep D. Saputra \\ ${ }^{2}$ Shane H. R. Ticoalu \\ ${ }^{2}$ Djon Wongkar
}

\author{
${ }^{1}$ Kandidat Skripsi Fakultas Kedokteran Universitas Sam Ratulangi Manado \\ ${ }^{2}$ Bagian Anatomi-Histologi Fakultas Kedokteran Universitas Sam Ratulangi Manado \\ Email: asep.dirga.saputra@gmail.com
}

\begin{abstract}
High level of plasma LDL-cholesterol concentrations is one of the cause of atherosclerosis that may result in cardiovascular diseases (CVD), such as coronary heart disease (CHD) and stroke. Exercise can improve plasma LDL-cholesterol concentrations. A type of exercise, poco-poco, is categorized to the aerobic gymnastics. This study aimed to know the influence of poco-poco to plasma LDL-cholesterol concentrations. This was an experimental study with one group prestest-posttest design. Samples were 25 female students of 2013 batch Pharmacy study program of Sam Ratulangi University Manado that were chosen with purposive sampling. Samples did poco-poco gymnasticss three times a week for four consecutive weeks. The results showed that after four weeks of poco-poco there was an increase of the average of plasma LDL-cholesterol concentrations for $1.120 \mathrm{mg} / \mathrm{dl}$, but this increase was not statistically significant $(p>0.05)$. Conclusion: There was no significant influence of doing poco-poco for four weeks to plasma LDL-cholesterol concentrations. Keywords: poco-poco gymnastics, low density lipoprotein
\end{abstract}

\begin{abstract}
Abstrak: Tingginya kadar kolesterol-LDL darah merupakan penyebab utama terjadinya aterosklerosis yang berujung pada munculnya penyakit kardiovaskular (PKV), seperti penyakit jantung koroner (PJK) dan stroke. Olahraga merupakan salah satu cara yang bisa digunakan untuk memperbaiki kadar kolesterol-LDL darah. Senam poco-poco termasuk dalam olah raga dengan kategori senam aerobik. Penelitian ini bertujuan untuk mengetahui pengaruh senam poco-poco terhadap kadar kolesterol-LDL darah. Penelitian ini bersifat eksperimental dengan desain one group prestest-posttest. Sampel penelitian ialah mahasiswa Fakultas MIPA Program Studi Farmasi Universitas Sam Ratulangi Manado Angkatan 2013 sebanyak 25 orang yang dipilih secara purposive sampling. Sampel melakukan senam poco-poco sebanyak tiga kali dalam seminggu selama empat minggu. Hasil penelitian memperlihatkan bahwa setelah melakukan senam poco-poco selama empat minggu terjadi peningkatan rata-rata kadar kolesterol-LDL darah sebanyak $1,120 \mathrm{mg} / \mathrm{dl}$, namun perubahan ini tidak bermakna secara statistik $(p>0,05)$. Simpulan: Tidak terdapat perubahan yang bermakna secara statistik terhadap kadar kolesterol-LDL darah setelah melakukan senam poco-poco selama empat minggu
\end{abstract}

Kata kunci: senam poco-poco, low density lipoprotein

Olahraga mempunyai pengaruh yang sangat baik bagi kesehatan. Banyak manfaat yang bisa didapatkan dari berolahraga, mulai dari mencegah suatu penyakit sampai dengan mengobatinya. Penurunan kadar lemak dan kolesterol dalam darah, peningkatan fungsi kardiovaskular dan respirasi, dan pencegahan penyakit jantung koroner (PJK) merupakan beberapa contoh manfaat dari berolahraga. ${ }^{1,2}$

Banyak sekali jenis olahraga yang 
sebenarnya bisa dilakukan sehari-hari, misalnya bersepeda, berenang, bermain sepakbola, jogging, dan lain-lain. ${ }^{2}$ Salah satu jenis olahraga yang mudah dilakukan dan digemari oleh para wanita, baik yang muda maupun tua, yaitu senam aerobik. ${ }^{3}$ Senam poco-poco digolongkan sebagai salah satu contoh dari senam aerobik karena kontinuitas gerakannya dan melibatkan banyak kelompok otot yang berkontraksi. Senam ini merupakan senam yang khas berasal dari daerah Sulawesi Utara. ${ }^{4}$

Di era kemajuan ilmu pengetahuan dan teknologi seperti sekarang ini, makin sibuknya pekerjaan seseorang menyebabkan waktu untuk berolahraga menjadi berkurang atau tidak ada, sehingga aktivitas fisik sehari-hari berkurang. Hal ini sering didapatkan pada kelompok mahasiswa, dosen, karyawan, dan lain-lain. Aktivitas yang kurang tersebut akan memberikan dampak negatif terhadap kesehatan, yaitu dapat meningkatkan prevalensi penyakit tidak menular (PTM), seperti hipertensi, penyakit kardiovaskular (PKV), dan dislipidemia.,

Dislipidemia diartikan sebagai suatu kelainan pada jumlah lipid, termasuk kolesterol, dan juga lipoproteinnya. Dislipidemia sangat erat kaitannya dengan penyakit kardiovaskular. Salah satu bentuk dari dislipidemia ialah hiperkolesterolemia yang ditandai dengan peningkatan kadar kolesterol Low Density Lipoprotein (kolesterol-LDL). Kolesterol-LDL merupakan suatu lipoprotein atau alat pengangkut yang paling banyak mengandung kolesterol, yaitu sekitar 45\%, dibandingkan dengan jenis lipoprotein lainnya. Fungsi utama kolesterol-LDL ialah membawa kolesterol ke berbagai jaringan perifer di seluruh tubuh. Namun, ada juga kolesterolLDL yang mengendap di pembuluh darah dan menyebabkan aterosklerosis. ${ }^{6-8}$

$$
\text { Menurut data World Heart }
$$

Organization (WHO), angka kematian yang disebabkan oleh penyakit tidak menular secara global mencapai sekitar 38 juta kasus setiap tahun. Dari angka ini, yang disebabkan oleh penyakit kardiovaskular mencapai 17,5 juta kasus. Faktorfaktor yang berhubungan dengan hal tersebut ialah merokok, aktivitas fisik yang kurang, dan diet yang tidak sehat. ${ }^{9}$ Khusus di Indonesia, kadar kolesterol-LDL yang termasuk dalam kategori tinggi dan sanggat tinggi pada penduduk yang berumur di atas 15 tahun, yaitu sebanyak 13,4\% untuk lakilaki dan $17,6 \%$ untuk perempuan. ${ }^{10}$

Masalah kadar kolesterol-LDL yang tinggi tersebut sebenarnya dapat diatasi dengan senam aerobik. Berdasarkan suatu penelitian, senam aerobik yang dilakukan sebanyak tiga kali dalam seminggu selama enam minggu dikatakan dapat menurunkan kadar kolesterol-LDL darah sekitar 9\%. ${ }^{7}$ Berdasarkan pada hal ini, perlu dilakukan suatu penelitian lain mengenai pengaruh senam aerobik terhadap kadar kolesterolLDL darah, namun dengan jenis senam yang berbeda, yaitu senam poco-poco.

\section{METODE PENELITIAN}

Jenis penelitian yang digunakan dalam penelitian ini ialah penelitian eksperimen dengan desain one group pretest-posttest yang dilaksanakan di Aula Kampus Kleak dan Laboratorium Klinik Patra selama bulan Oktober sampai dengan Desember 2014.

Sampel penelitian yang digunakan ialah Mahasiswa Fakultas MIPA Program Studi Farmasi Universitas Sam Ratulangi Manado Angkatan 2013 yang berjumlah 25 orang yang dipilih secara purposive sample dengan memenuhi kriteria inklusi, yaitu IMT normal $\left(18,5-25,9 \mathrm{~kg} / \mathrm{m}^{2}\right)$, serta kriteria eksklusi, yaitu perokok aktif, menjalani program diet tinggi lemak, mengikuti latihan fisik atau kebugaran (fitness) secara rutin, menggunakan obat statin, dan riwayat mengalami masalah muskuloskeletal.

Variabel bebas ialah senam poco-poco, sedangkan variabel terikat ialah kadar kolesterol-LDL darah. Senam poco-poco dilakukan sebanyak tiga kali dalam seminggu selama empat minggu dengan durasi selama 47 menit (30 menit 
pemanasan, 45 menit gerakan inti, dan 1 menit 30 detik pendinginan). Kadar kolesterol-LDL darah diukur pada pagi hari pertama melakukan senam poco-poco pertama kali (pretest) dan satu hari (besok paginya) setelah melakukan senam pocopoco terakhir kali (posttest) dengan terlebih dahulu dipuasakan selama 8-12 jam.

\section{HASIL PENELITIAN}

Deskripsi karakteristik sampel penelitian berdasarkan usia dapat dilihat pada Tabel 1.

Tabel 1. Distribusi sampel penelitian berdasarkan usia

\begin{tabular}{ccc}
\hline $\begin{array}{c}\text { Umur } \\
\text { (tahun) }\end{array}$ & Frekuensi & Persentase \\
\hline 18 & 18 & 72,0 \\
19 & 7 & 18,0 \\
\hline Total & 25 & 100,0 \\
\hline
\end{tabular}

Deskripsi karakteristik sampel penelitian berdasarkan tinggi badan dapat dilihat pada Tabel 2.

Tabel 2. Deskripsi sampel penelitian berdasarkan tinggi badan

\begin{tabular}{ccccc}
\hline & Rerata & SD & Min & Max \\
\hline $\begin{array}{c}\text { Tinggi } \\
\text { badan } \\
(\mathrm{cm})\end{array}$ & 153,6 & 4,8 & 146,7 & 169,1 \\
\hline
\end{tabular}

Deskripsi karakteristik sampel penelitian berdasarkan berat badan, dan indeks massa tubuh (IMT) dapat dilihat pada Tabel 3.

Tabel 3. Deskripsi sampel penelitian berdasarkan berat badan dan IMT

\begin{tabular}{ccccc}
\hline & \multicolumn{2}{c}{ Berat badan $(\mathrm{kg})$} & \multicolumn{2}{c}{ IMT $\left(\mathrm{kg} / \mathrm{m}^{2}\right)$} \\
\cline { 2 - 5 } & Pre & Post & Pre & Post \\
\hline Rerata & 51,9 & 51,3 & 22,0 & 21,7 \\
SD & 6,3 & 6,0 & 1,9 & 1,8 \\
Min & 43,5 & 42,0 & 18,8 & 18,8 \\
Max & 74,0 & 71,5 & 25,9 & 25,2 \\
\hline
\end{tabular}

Deskripsi karakteristik sampel penelitian berdasarkan kadar kolesterolLDL darah dapat dilihat pada tabel 4.

Tabel 4. Deskripsi berdasarkan kadar kolesterol-LDL darah

\begin{tabular}{ccc}
\hline & \multicolumn{2}{c}{ Kadar kolesterol-LDL } \\
& darah \\
\cline { 2 - 3 } & Pre & Post \\
\hline Rerata & 111,9 & 113,0 \\
Standar deviasi & 26,7 & 13,5 \\
Minimum & 68 & 71 \\
Maximum & 168 & 168 \\
\hline
\end{tabular}

Hasil analisis terhadap kadar kolesterol-LDL darah menggunakan uji Paired T-Test (uji t berpasangan) dengan interval kepercayaan 95\% ditampilkan pada tabel 5.

Tabel 5. Analisis terhadap kadar kolesterolLDL darah

\begin{tabular}{ccc}
\hline & $\begin{array}{c}\text { Selisih } \\
\text { rerata }\end{array}$ & $\begin{array}{c}p \text {-value } \\
\text { (Nilai p) }\end{array}$ \\
\hline $\begin{array}{c}\text { Kadar } \\
\text { Kolesterol-LDL } \\
\text { Darah }\end{array}$ & $-1,120$ & $0,703^{*}$ \\
\cline { 2 - 2 } *tidak bermakna (p>0,05) & \\
BAHASAN & &
\end{tabular}

Dari hasil analisis terhadap usia sampel penelitian, didapatkan hasil bahwa sampel penelitian terbagi menjadi dua kelompok usia, yaitu usia 18 tahun dan usia 19 tahun. Usia terbanyak terdapat pada kelompok usia 18 tahun dengan jumlah 18 orang (72\%), sedangkan kelompok usia 19 tahun lebih sedikit dengan jumlah 7 orang (18\%).

Tingkatan usia berpengaruh terhadap keadaan kadar kolesterol-LDL darah seseorang. Pada usia anak-anak sampai remaja akhir, kadar kolesterol-LDL darah akan menurun, sedangkan pada usia dewasa (20-50 tahun) kadar kolesterolLDL darah akan meningkat, namun terjadi kembali penurunan kadar kolesterol-LDL darah ketika seseorang berusia lanjut. ${ }^{11}$ 
Untuk tinggi badan (tabel 2), pada penelitian didapatkan bahwa nilai rata-rata tinggi badan sampel penelitian 153,6 \pm 4,8 cm dengan nilai minimum sebesar 146,7 cm dan nilai maximum sebesar 169,1 cm.

Karakteristik lain dari sampel penelitian yang dinilai, selain usia dan tinggi badan, ialah berat badan dan indeks massa tubuh (IMT). Pada penelitian (tabel 3) didapatkan hasil bahwa nilai rata-rata berat badan sampel penelitian sebelum melakukan senam poco-poco ialah $51,9 \mathrm{~kg}$ $\pm 6,3 \mathrm{~kg}$, serta nilai minimum dan maximum ialah 43,5 kg dan $74 \mathrm{~kg}$, sedangkan nilai rata-rata berat badan sampel penelitian setelah melakukan senam poco-poco ialah $51,3 \pm 6,0 \mathrm{~kg}$, nilai minimum $42 \mathrm{~kg}$ dan maximum 71,5 kg.

Untuk indeks massa tubuh, didapatkan hasil bahwa nilai rata-rata indeks massa tubuh sampel penelitian sebelum

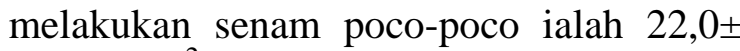
$1,9 \mathrm{~kg} / \mathrm{m}^{2}$, serta nilai minimum dan maximum ialah $18,8 \mathrm{~kg} / \mathrm{m}^{2}$ dan $25,9 \mathrm{~kg} / \mathrm{m}^{2}$, sedangkan nilai rata-rata indeks massa tubuh sampel penelitian setelah melakukan senam poco-poco ialah $21,7 \pm 1,8 \mathrm{~kg} / \mathrm{m}^{2}$, nilai minimum $18,8 \mathrm{~kg} / \mathrm{m}^{2}$ dan maximum $25,2 \mathrm{~kg} / \mathrm{m}^{2}$. Dari data tersebut, dapat dilihat bahwa terjadi penurunan terhadap berat badan dan indeks massa tubuh sampel penelitian.

Berdasarkan hasil analisis terhadap kadar kolesterol-LDL darah (tabel 5) didapatkan hasil bahwa selisih rata-rata antara kadar kolesterol-LDL pretest dan posttest yaitu sebesar $1,120 \mathrm{mg} / \mathrm{dL}$, dengan nilai kadar kolesterol-LDL posttest yang lebih besar. Ini berarti bahwa terjadi peningkatan kadar kolesterol-LDL darah setelah melakukan senam poco-poco. Namun, peningkatan ini tidak bermakna, apabila dilihat dari nilai p-nya. Nilai p yang lebih besar dari 0,05 ( $>00,05)$ pada tabel 5, menandakan bahwa tidak terjadi perubahan yang bermakna secara statistik pada kadar kolesterol-LDL darah.

Hasil yang didapatkan pada penelitian ini, berbeda dengan penelitian-penelitian yang telah dilakukan sebelumnya oleh para peneliti yang lain. Pada sebuah penelitian yang dilakukan oleh Asmarantaka dkk, didapatkan hasil bahwa senam aerobik selama enam minggu dapat menurunkan kadar kolesterol-LDL darah secara bermakna $(p<0,05)$ dengan selisih rataratanya mencapai $9 \mathrm{mg} / \mathrm{dL}$.

Penyebab terjadinya perbedaan hasil pada penelitian ini dengan hasil yang didapatkan oleh Asmarantaka dkk, kemungkinan diakibatkan oleh perbedaan pada lamanya senam yang dilakukan, yaitu pada penelitian ini selama empat minggu, sedangkan pada penelitian Asmarantaka dkk menggunakan enam minggu senam. Selain itu, perbedaan lain yang ada pada kedua penelitian tersebut, yaitu pada sampel penelitian yang digunakan. Pada penelitian oleh Asmarantaka dkk, sampel yang digunakan ialah wanita-wanita yang sudah secara rutin melakukan senam aerobik, sedangkan pada penelitian ini digunakan wanita-wanita yang sebelumnya tidak rutin berolahraga.

Frekuensi dan durasi suatu latihan yang dilakukan sangat berpengaruh terhadap kadar kolesterol-LDL seseorang. Jadi semakin sering dan lama suatu latihan dilakukan, maka latihan tersebut lebih berpeluang untuk menurunkan kadar kolesterol-LDL darah, apabila juga disertai dengan pengaturan pola makan, yaitu dengan diet rendah lemak. ${ }^{11,12}$

Berbeda dengan penelitian oleh Asmarantaka dkk, penelitian yang dilakukan oleh Varady dkk justru mendukung hasil pada penelitian ini, yaitu pada hasil penelitiannya didapatkan hasil bahwa latihan aerobik selama 12 minggu tanpa diet rendah kalori tidak dapat membuat perubahan yang bermakna ( $>0,05)$ terhadap kadar kolesterol-LDL darah, dibandingkan dengan diet rendah kalori tanpa latihan selama 12 minggu. ${ }^{13}$ Persamaan dalam hasil tersebut, kemungkinan karena dalam penelitian ini memang tidak dilakukan pengaturan yang ketat terhadap pola makan sampel penelitian, hal inilah yang menyebabkan tidak terjadinya perubahan yang bermakna 
terhadap kadar kolesterol-LDL sampel penelitian. Hal ini sejalan dengan teori yang mengatakan bahwa latihan yang tanpa disertai diet rendah lemak, pada banyak kasus, tidak dapat menurunkan kadar kolesterol-LDL darah. Latihan yang dilakukan sendiri (tanpa diet) hanya mampu mengubah bentuk partikel LDL, yaitu dari small dense LDL menjadi large dense LDL, tanpa mengubah jumlah kadar kolesterol-LDL darah total. ${ }^{11,12}$

\section{SIMPULAN}

Senam poco-poco yang dilakukan selama empat minggu tidak memberikan perubahan yang bermakna secara statistik terhadap kadar kolesterol-LDL darah Mahasiswi Fakultas MIPA Program Studi Farmasi Universitas Sam Ratulangi Manado Angkatan 2013.

\section{SARAN}

Perlu dilakukan penelitian lebih lanjut mengenai pengaruh senam poco-poco terhadap kadar kolesterol-LDL darah dengan sampel dari populasi yang berbeda dan lebih besar serta waktu penelitian yang lebih lama. Selain itu, perlu juga dilakukan kontrol yang lebih ketat terhadap faktorfaktor lain yang dapat mempengaruhi kadar kolesterol-LDL darah.

\section{UCAPAN TERIMA KASIH}

Ucapan terima kasih disampaikan kepada dr. George N. Tanudjaja, MS, $\mathrm{PA}(\mathrm{K})$ dan Dr. dr. Sunny Wangko, M.Si, $\mathrm{PA}(\mathrm{K})$ selaku dosen penguji skripsi. Juga, kepada semua pihak, baik secara langsung maupun tidak langsung, yang telah menumbuhkan ide dan gagasan bagi penulis.

\section{DAFTAR PUSTAKA}

1. Utomo GT, Junaidi S, Rahayu S. Latihan senam aerobik untuk menurunkan berat badan, lemak, dan kolesterol. Journal of Sport Sciences and Fitness. 2012;1:6-10.

2. Indriyani $P$, Supriyanto $H$, Santoso A. Pengaruh latihan fisik; senam aerobik terhadap penurunan kadar gula darah pada penderita DM tipe 2 di wilayah puskesmas Bukateja Purbalingga. Media Ners. 2007;1:89-99.

3. Jayanti Y, Rumampuk JF, Supit W. Pengaruh latihan zumba terhadap nilai FEV1 (Forced Expiratory Volume in one second) [jurnal skripsi]. Manado: Universitas Sam Ratulangi.

4. Rattu AJ, Rampengan JJ. Perubahan kadar high density-lipoprotein setelah senam poco-poco. Buletin Penelitian Kesehatan. 2004;32:43-8.

5. Cooper AJ, Brage S, Ekelund U, Wareham NJ, Griffin SJ, Simmons RK. Association between objectively assessed sedentary time and physical activity with metabolic risk factors among people with recently diagnosed type 2 diabetes. Diabetologia. 2014;57:73-82.

6. Adam JM. Dislipidemia. Dalam: Sudoyo AW, Setiyohadi B, Alwi I, Simadibrata M, Setiati S, editors. Buku ajar penyakit dalam. Jilid III. Edisi ke-5. Jakarta: Interna Publishing; 2010. h. 1984-7.

7. Asmarantaka GC, Sutyarso, Wahyuni A. Perubahan kadar HDL dan LDL sebagai respon latihan aerobik pada aerobik dan fitness center sonia Bandar Lampung [jurnal skripsi]. h. 85-91.

8. Wulandari AD. Hubungan dislipidemia dengan kadar ureum dan kreatinin darah pada penderita nefropati diabetik [skripsi published]. Semarang: Universitas Diponegoro; 2012.

9. World Health Organization. Noncommunicable diseases. 2015 Januari [diakses tanggal : 26 Januari 2015]. Tersedia dari :

http://www.who.int/mediacentre/factsh eets/fs355/en/

10.Badan Penelitian dan Pengembangan Kesehatan Kementerian Kesehatan RI. Riset kesehatan dasar 2013. 2013. h. 259-60.

11.Moffat RJ, Stamford B, editor. Lipid metabolism and health. Boca Raton: Taylor \& Francis Group; 2006. h. 32133, 177-8.

12.Levine TB, Levine BA. Metabolic syndrome and cardiovascular disease. Philadelpia: Saunders Elsevier; 2006. h. 314-5.

13.Varady KA, Bhutani S, Klempel MC, 
Saputra, Ticoalu, Wongkar: Pengaruh senam poco-poco...

Kroeger CM. Comparison of effects of size in obese adults. Lipids in Health diet versus exercise weight loss and Disease. 2011;10:1-5. 